\title{
THOMAS HILLIER AND PERCUTANEOUS NEPHROSTOMY
}

\author{
DAVID A. BLOOM, M.D. \\ ROBERT J. MORGAN, F.R.C.S. \\ PETER L. SCARDINO, M.D.
}

From the Department of Surgery, University of Michigan, Ann Arbor, Michigan, and Urology Department, Royal Free Hospital Medical School, London, England, and Memorial Medical Center, Savannah, Georgia

Percutaneous nephrostomy has revolutionized urologic practice. Goodwin, Casey, and Woolf's landmark report in $1955^{1}$ described percutaneous trocar nephrostomy for temporary drainage of hydronephrosis in 16 patients. Following a twenty-five year period of relative dormancy, percutaneous access to the upper urinary tract became a fundamental diagnostic and therapeutic tool. The literature contains isolated reports of diagnostic percutaneous renal punctures prior to Goodwin. ${ }^{2-5}$ Neglected in the older literature, however, is Thomas Hillier's ${ }^{6}$ description of therapeutic percutaneous renal decompression in 1865 .

\section{Hillier's Case Reort}

Hillier's case report in 1865 was entitled "Hydronephrosis in a boy four years old, repeatedly tapped; recovery." This brief clinical note provided no identifying features of the patient and no long-term follow-up.

"The patient when born had great enlargement of the abdomen, simulating ascites, for which it was mistaken until he was nearly four years old. It was then ascertained to be an enormous cyst springing from the right lumbar region. From its great size it caused difficulty of breathing and prevented his walking. The cyst was tapped in front, and 102 fluid ounces of clear non-albuminous fluid was drawn off, having all the characters of dilute urine. The fluid rapidly re-collected, and on a second tapping was found to be albuminous and purulent, but still to contain a considerable quantity of urea. Attempts were made to establish a permanent fistula anteriorly, and then posteriorly; but on each occasion the fluid after a time ceased to flow. Much irritation and depression followed the several tappings, so that the patient's life seemed to be endangered. After one of the operations a quantity of fluid was passed from the bladder exactly similar to that from the cyst, and quite unlike what was usually passed from the urethra; a temporary communication thus obviously being established between the cyst and the blad- der. The patient has now been left without operation for some months, and has regained his strength; but the cyst remains, varying from time to time in size, and his urine is often purulent and fetid. It is presumed that there is some congenital malformation of the right ureter which renders it liable to occlusion, but admits, under some circumstances, of passage of fluid."

"Cases of congenital hydronephrosis due to obliteration of the ureter were quoted, proving fatal in infancy; one case of an enormous cyst, apparently a dilated kidney, resulting from obliteration of the ureter, in a woman who lived to the age of twenty-three years; and one of a double hydronephrosis in a youth who lived to the age of seventeen years. In the latter case the ureter on one side was much constricted, and on the other entered the pelvis of a kidney obliquely, and was guarded by a valvular obstruction."6

\section{Subsequent References to the Case}

Hillier's pediatric textbook, published in 1868, included a follow-up to the previous case report:

“Tapping was several times repeated, but only with temporary relief. There is obviously an obstruction of the ureter due to a congenital defect; there is, however, at intervals a communication established between the kidney and the bladder, because on several occasions when the accumulation has reached a certain point there has been an unusual flow of urine from the urethra which has partially reduced the swelling. The case is a very remarkable one; not long ago the boy was living and no new symptoms had occurred. The swelling is so great as to prevent him walking about, though he is 8 years old, and it interferes much with his respiration and general nutrition." 7

The final reference to this patient was discovered in Hillier's last set of case notes. Therein the child is identified as Johnny Ross, eight years old, and the diagnosis is given as "hydronephrosis, ctc, etc." 8 In the notes, Hillier recounts how he had first seen the boy in March, 1863, and had planned to tap the kidney then, but deferred after the swelling partially 
subsided. Percutaneous aspiration was eventually performed in February, 1864, and repeated periodically over the next few years. A final admission to the Great Ormond Street Hospital for Sick Children occurred on July 16, 1868: "He was brought in by the father as he thought he wanted tapping." It is not specifically recorded that the child was tapped at that time, but he became febrile after admission and deteriorated until his death on August 5, 1868. Postmortem examination was performed 20 hours after death. The large right lumbar cyst was unquestionably a hydronephrotic kidney. Hillier's notes described classic giant hydronephrosis with ureteropelvic junction obstruction: the cyst was observed “. . . to be in the situation of the right kidney, no kidney structure being visible externally. . . . The ureter is found proceeding from the lower part of the cyst, attached for about an inch to the wall (apparently by the reflection of peritoneum) to the lower and right of the cyst. The cyst contained $83 \mathrm{oz}$. of fluid having pale urinous appearance and urinous smell. Spc gra 1002, very slightly acid, and with merely a trace of albumen, presently under the microscope merely a few broken down cells of large size. . . . The right ureter, natural size, or rather small, a dressing probe being passed up from the bladder in to the ureter with some little difficulty the sides being in close apposition but not adherent, the most contracted part being close to the bladder where the probe is grasped by the ureter; after passing the probe to within 2 inches of the cyst, fluid can be squeezed out of the cyst through the ureter into the bladder, but comes slowly and with difficulty." The left kidney "seen in situ does not appear much enlarged," but the left ureter was mildly dilated and obstructed distally by calculous matter. Johnny Ross probably died of a stone obstructing his contralateral normal kidney.

\section{Analysis of Hillier's Case}

Percutaneous drainage of a kidney was unprecedented in Hillier's era. The hydronephrotic mass caused breathing and walking difficulty for the four-year-old boy, and Hillier must have felt there was no alternative to intervention. Indwelling tube drainage would have been a disaster without the protection of sterile technique and antibiotics. His initial plan to tap the mass was deferred when its size seemed to decrease, and he followed the patient for eleven months before the first percutaneous aspiration. The initial success gave him courage to tap the kidney repeatedly, when it seemed necessary. The title of his case report indicates that he knew he was relieving a hydronephrotic kidney. The massive size of the renal pelvis permitted an anterior tap, which yielded more than $3 \mathrm{~L}$ of clear urine. On subsequent occasions he drained the mass posteriorly.

Hillier performed urine analysis and referred to the quantity of urea in the fluid. The first puncture probably infected the system because successive aspirations were purulent. Hillier hoped to create a "permanent fistula" with a trocar. The fact that such a pyelostomy never persisted, and the additional observation of periodic passage of grossly purulent urine per urethram, testifies to the incomplete degree of ureteropelvic junction obstruction.

His experience with this case gave him some insight into the pathophysiology and intermittency of ureteropelvic junction obstruction, a feature he recognized in comments at the end of the first paragraph of the initial case report. The patients described in the second paragraph demonstrate Hillier's precocious grasp of the spectrum of ureteropelvic junction obstructions.

Hillier referred to this patient in his pediatric textbook three years after the initial case report and admitted that the tapping brought only temporary relief, although the boy remained alive and generally well without new symptoms. Hillier was convinced that the problem was congenital intermittent obstruction involving the ureter. This belief was supported by his observation that the mass receded in size after an unusually large urinary output per urethram.

The last reference to this patient was found in Hillier's final book of case notes written late in 1868, the same year as the textbook. Hillier described a hospital admission on July 16 and identified the boy as Johnny Ross, who by then was eight years old. The reason for the admission is not clear, other than that the father thought retapping was necessary. In fact, the child seemed quite well: ". . . on admission he was tolerably lively, sat up and eat well talked, and was not much distressed in his breathing. He continued about the same until the 20th when he was sick, much depressed Temp $103^{\circ}$ drowsy and listless not noticing anything; his face flushes; he will not take food except liquid." ${ }^{8}$ Hillier did not record that the kidney was tapped in this admission, although the boy had been brought to the hospital for that purpose. Johnny Ross was well for four days after admission before his condition deteriorated, and a subsequent downhill course was recorded until death on August 5.

Hillier probably performed the autopsy himself, and the 6-page handwritten report is included among his case notes. There was no evidence of ascites or chronic peritoneal inflammation. The liver was described as healthy except for some tubercles on the surface. The cause of death is not clear, but 
most likcly was related to the obstructing contralateral distal ureteral stone. The precise anatomic details of the postmortem report leave no doubt that Hillier did, in fact, manage a giant hydronephrotic kidney by intermittent percutaneous drainage over a period of four and one-half years. Hillier has not been recognized for his contribution of purposeful therapeutic percutaneous renal access, in part because of his untimely death which cut short a career that held great promise.

The Life of Dr. Thomas Hillier

Hillier was born in 1831 at Newmarket in Gloucestershire. We have no details of his family other than he had a younger brother Peter Playne Hillier. Thomas Hillier studied in London at University College, taking his M.B. in 1845, his B.A. in 1849 , and an M.D. in 1855 . The M.R.C.S. was awarded to him in 1852 and the F.R.C.P. in $1867 .^{9}$ He married in 1855 and had 2 children with his wife Susan. ${ }^{10}$ The Hilliers first lived on Upper Gower Street, but moved between 1865-1866 to 21 Queen Anne Street. ${ }^{11}$

Following an appointment as Resident Medical Officer at University College Hospital, he was selected from a number of distinguished competitors for the new post of Medical Officer of Health in St. Pancras. His efforts in that capacity primarily involved public health and earned him wide respect in the twelve years he held the position. ${ }^{9}$ Hillier played a pivotal part in a matter of public health relating to the poisonous green dyes commonly used in wallpapers. One of his reports as the Medical Officer described the death of a young woman who had been employed making artificial flowers using arsenite of copper, also known as Vienna green or Scheele's green. The public furor aroused led to enactment of early industrial hygiene regulations. ${ }^{12}$

In addition to his work in general and sanitary medicine, Hillier pursued an interest in dermatology, culminating in his Handbook of Skin Diseases published in 1865, both in English and American editions. ${ }^{13}$ This became a standard manual of the time and led to his appointment as Physician of the Skin Department of the University College Hospital. In the preface to the text Hillier wrote: "I have often been asked, 'What is the best English book to read on skin diseases?' Not being able to answer this satisfactorily I determined to write a book such as I could recommend to the student." Among other credits in his preface, Hillier acknowledged the work of Gustav Simon, although no reason for this reference is apparent. Hillier's introduction comments that dermatology was poorly understood because of the confusing nomenclature: "A real knowl- edge of dermatology as will be of real service in practice can only be obtained by seeing the disease itself."

Pediatric medicine became Hillier's first clinical love. Early in his tenure as Health Officer of St. Pancras he attached himself to the newly opened Hospital for Sick Children at Great Ormond Street. He was selected as assistant physician in 1857 from a field of 5 candidates. ${ }^{14}$ Great Ormond Street first opened in 1852, largely due to the efforts of Dr. Charles West, and at the time of Hillier's initial appointment West and William Jenner were the only physicians. Athol Johnson was the surgeon, Samuel Cartwright was the surgeon-dentist, and C. M. Babington was the other assistant physician. These men comprised the Medical Officers. William Baly, Physician to Queen Victoria, was a member of the Committee of Management of the Hospital. After Baly's death in a train accident, ${ }^{15}$ Jenner was named Queen's Physician, and it was then, in 1862 , that Hillier became a full-fledged physician of the Hospital for Sick Children. ${ }^{14}$ Jenner served as a mentor for Hillier who dedicated Diseases of Children to him.

In the capacity of physician, Hillier issued his hydronephrosis case report in 1865 . Hillier was described as "Working assiduously in a field then but little cultivated, he soon became physician to the hospital and got wide reputation by those excellent clinical lectures which have lately been collected into one of the most practical treatises of the time." This book, Diseases of Children, was 402 pages long, unillustrated and, like the dermatology text, was published on both continents in 1868. Because the Hospital for Sick Children, in its early years, admitted patients only between the ages of two to twelve years, and concentrated mainly on medical problems, the textbook purposefully omitted diseases of infants and surgical conditions. The book's introduction offered a grim overview of pediatrics in 1868; "Of 1000 children born, 150 die within twelve months; 113 during the next four years; giving 263 or more than a quarter within five years of birth. During the next five years 34 die; during the next five years 18 more die; so that at 15 years of age only 684 remain of the 1000 born. Of those who survive very many bear permanent marks of imperfect development, of defective nutrition, or of actual disease, due to maladies contracted in early life." ${ }^{7}$ Hillier appreciated the special touch needed in pediatrics: "Children are good physiognomists and know those who are fond of them, so that the physician who loves children will usually have less trouble in examining a child than one who has no affection for them." 7 
Diseases of Children was accorded a favorable 2column review in The Lancet. ${ }^{16}$ The book had a long-lasting influence as through it Hillier was quoted many years after his death. For example, Meigs and Pepper's important pediatric text in 1886 referred to Hillier in at least 4 places (only 3 are mentioned in the index), with a curious reference to bloodletting. "In order that the younger practitioner may see the changes which have taken place in this respect, we shall quote the views of some of the more important authorities. . . . Dr Thomas Hillier, of London, says of bloodletting that it "is now for the most part discarded. I have never had occasion to resort to it." "'17

Hillier was active in the affairs of the Hospital at Great Ormond Street, participating in committee meetings and fund raising. In the centenary history of the Hospital for Sick Children, Higgins described Hillier's effort for dietary reform.

"In May, 1867, Dr. Hillier, by request, suggested ammendments to the patients' diet, as follows:

(1) Roast beef to be given for dinner on one day weekly.

(2) Convalescents to have pudding on three days a week.

(3) Green vegetables to be provided one day a week, except when very expensive.

(4) A slice of bread and butter for supper when desired." ${ }^{18}$

In addition to his two books and the case herein discussed, Hillier wrote at least 12 other clinical papers on problems as diverse as leprosy and suicide, although the majority of his articles concerned pediatric problems. ${ }^{11}$

A single portrait of Hillier was located among papers at Great Ormond Street Hospital Archives (Fig. 1). Because the photograph describes him as Physician at Great Ormond Street Hospital, it must have been taken in or after 1862. Hillier is shown as a distinguished, thin, and unequivocally balding gentleman wearing a frock coat and seated in a leather button-tufted chair. He is curling a muttonchop side burn with his left hand which bears a ring on the little finger.

1868 was the last year of Hillier's life. An episode of hemoptysis ${ }^{9}$ heralded extensive pulmonary tuberculosis. ${ }^{19}$ Hillier planned a therapcutic rest on a cruise to the Cape of Good Hope, but odd circumstances prevented this. His younger brother, leaving Hillier's home after a farewell visit, was fatally thrown from his carriage and brought back to Hillier's house where he died within three days. ${ }^{7} \mathrm{Hil}$ lier's own health deteriorated rapidly, abetted by depression, and he died a fortnight later on November 11,1868 , at age thirty eight. The cause of death was listed as acute mania for ten days and phthisis (an archaic term for the progressive wasting of pulmonary tuberculosis) for five months. ${ }^{20}$ He left a wife,

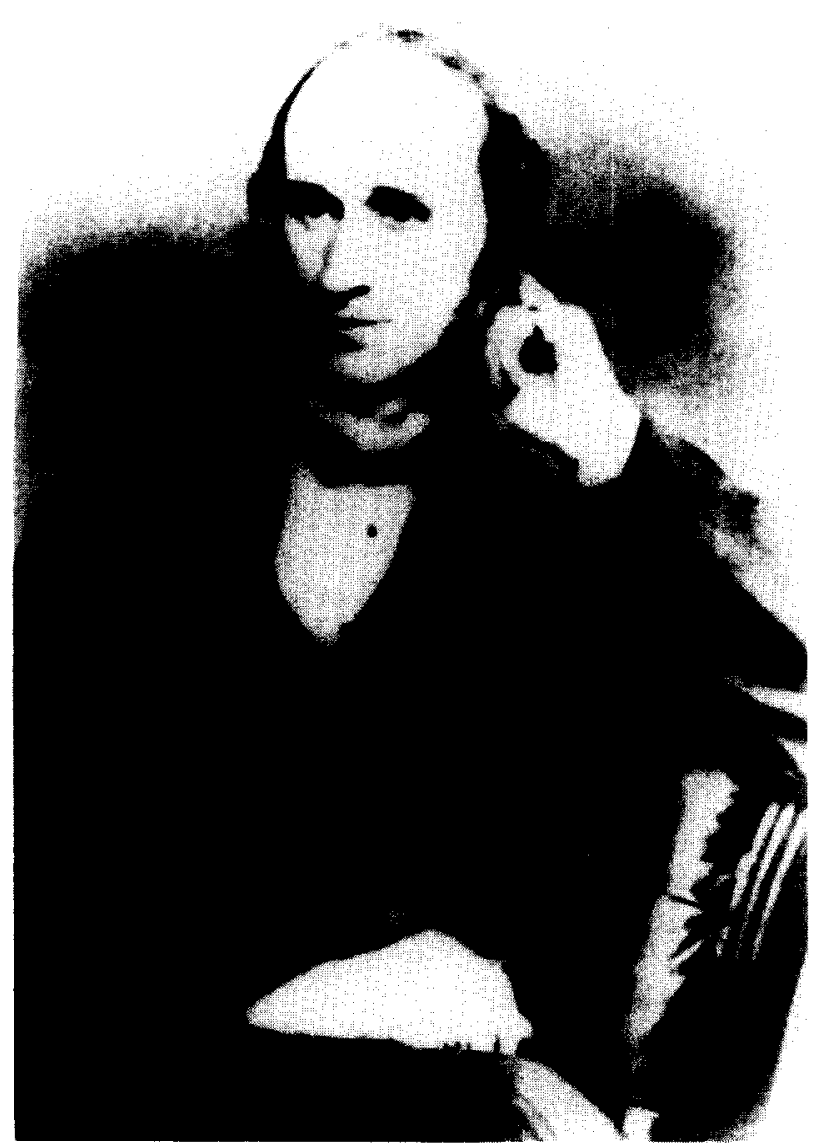

Figure 1. Dr. Thomas Hillier, Physician, Great Ormond Street Hospital for Sick Children, 18311868 (reproduced by permission, Board of Governors, Hospital for Sick Children, Great Ormond Street).

two children, and an estate of less than $£ 5,000 .{ }^{10}$ (By comparison, Hillier's mentor, William Jenner, died in 1898 with an estate of $£ 375,000$. $)^{21}$

On December 10, 1868, the minutes of the Great Ormond Street Hospital Committee of Management recorded the contribution by Mrs. Hillier of $6 \mathrm{vol}$ umes of Notes of Cases treated at the hospital. ${ }^{\text {it }}$ These were recently discovered in storage at the Qucen Elizabcth Hospital in Hackney by Jules Kosky, Honorary Assistant Archivist at Great Ormond Street. A seventh volume, Hillier's final one, was located in the library of the Institute for Child Health among the papers of Dr. Charles West, the founder of the Great Ormond Street Hospital.

Hillier's case notes display great attention to detail and a precise approach to patient care. He often performed urine analysis that included measurement of acidity, specific gravity, analysis of chemistries including albumin and uric acid, as well as microscopic examination of sediment. Aside from 
making diagnosis and providing symptomatic relief, he was unable to do much to alter the courses of most diseases he saw, such as renal colic, seizures, or paralysis. His notes, however, record a number of tracheotomies, often with favorable outcome. Aside from these and his experience with percutaneous renal access, he shied away from surgical procedures. The last case book records 88 children treated in his last year of life. Sixteen of these children, including Johnny Ross, had fatal outcomes.

Hillier's two children were not identified in his papers. Hillier's wife, Susan, died at age sixty $\operatorname{six}^{22}$ in 1895, and her will left an estate of $£ 1,547$ to "Thomas Ernest Hillier, surgeon,"23 This presumably was her son. No other primary sources referred to the other child until this entry in the Grcat Ormond Street Hospital Visitors' Book on January 13, 1932: "Edith Maria Hillier, of 14 Randolph Gardens, daughter of the late Thomas Hillier."24

University of Michigan 2918A Taubman Center, Box 0330

Ann Arbor, Michigan 48109 (DR. BLOOM)

ACKnOwledgments: To Jules Kosky, Honorary Assistant Archivist of the Peter Pan Gallery (The Archives of the Hospital for Sick Children, Great Ormond Strect), and to the Office of the Redevelopment Appeal of the Great Ormond Street Hospital for Sick Children, London, England. Quotations from Hospital Minutes are printed with the kind permission of the Board of Governors of the Hospital for Sick Children. Special thanks are due to The Wellcome Institute for the History of Medicine and Robin Price, Deputy Librarian and Curator of the American Collections. Sister Fay, now of the Nephrology Department in the Institute of Child Health, has been an unparalleled catalyst in the training of two of the authors (DAB and $\mathrm{RJM}$ ) and provided a vital link in the development of this small historical work.

\section{References}

1. Goodwin WE, Casey WC, and Woolf W: Percutaneous trocar (needle) nephrostomy in hydroncphrosis, J $\Lambda$ M $\Lambda$ 157: 891-894 (1955)

2. Fish GW: Large solitary serous cysts of the kidney, JAMA 112: 514-518 (1939).

3. Wheeler BC: Use of the aspirating needle in the diagnosis of solitary renal cyst. N Engl J Med 226: 55-57 (1942).

4. Lindblom K: Percutaneous puncture of renal cysts and tumors, Acta Radiol 27: 66-72 (1946).

5. Weens HS, and Florence TJ: The diagnosis of hydronephrosis by percutaneous renal puncture, J Urol 72: 589-595 (1954).

6. Hillier T: Hydronephrosis in a boy four years old, repeatedly tapped; recovery, Proc R Med Chir Soc Lond 5: 59-60 (1865)

7. Hillier T: Diseases of Children. A Clinical Treatise, Philadelphia, Lindsay and Blakiston, 1868, pp 2, 20, 293.

8. Hillier T: Case Notes, Final Volume, December 31, 1867, p 230.

9. Anonymous: Obituary-Thomas Hillier, M.D. etc.. Med Times Gaz 2: 23 (1868).

10. Hillier T: Last Will and Testament, Filed 1865, Somerset House, London.

11. Iondon and Provincial Medical Directory. London, John Churchill and Sons, 1855-1868 eds.

12. Brockington CF: Public Health in the Nineteenth Century, Edinburgh and London, E. and S. Livingston Ltd, 1965

13. Hillier T: Hand-Book of Skin Diseases For Students and Practitioners, Philadelphia, Blanchard and Lea, 1865.

14. Minutes, Committee of Management, Hospital for Sick Children, Great Ormond Street, London, November 11, 1857, and December 10, 1868

15. Anonymous: Death of Dr. Baly, Lancet 1: 122 (1861).

16. Anonymous: Book review-Diseases of Children. A Clinical Treatise, Lancet 2: 481 (1868).

17. Meigs JF, and Pepper W: A Practical Treatise on the Diseases of Children, Philadelphia, Blakiston Son \& Co, 1886, p 185.

18. Higgins TT: Great Ormond Street 1852-1952, Long Acre, London, Udhams Press Ltd, 1952.

19. Anonymous: Obituary-Thomas Hillier, M.D., FRCP, Lancet 7: 654 (1868)

20. Hillier T: Death Certificate, 1868 (District of Chelsea, County Middlesex), St. Catherines House, London.

21. Castiglioni A: A History of Medicine, translated by Krumbhaar EB, New York, Jason Aronson Inc., 1969, pp 821 822.

22. Hillier S: Death Certificate, 1895 (District of Wangford, County Suffolk), St. Catherines House, London.

23. Hillier S: Last Will and Testament, filed 1895, Somerset House, London.

24. Visitors' Book, Hospital for Sick Children, Great Ormond Street, London, England. 